\section{In This Issue - April 2020}

\author{
Serge Savary ${ }^{1}$
}

Published online: 11 April 2020

(C) International Society for Plant Pathology and Springer Nature B.V. 2020

\section{The International Year of Plant Health at Food Security}

The first article is a Review, and the first article of the Series: "Pathogens which Threaten Food Security. This Series is being published on the occasion of the Year of Plant Health, which has been declared by the United Nations for 2020 . The first article of the Series is written by Pr. Xianming Chen at Washington State University, USA: Pathogens which threaten food security: Puccinia striiformis, the wheat stripe rust pathogen.

The April 2020 Issue of Food Security includes 14 other articles.

The second article of the issue addresses a novel view of plant food production: Plant factories in the water-foodenergy Nexus era: a systematic bibliographical review. The concept of plant factory is concerned with the global $\mathrm{CO} 2$ emissions, pollution, over-fertilisation, deforestation, loss of arable land - which all are related with food production. The authors offer a view on one possibility of securing food without these drawbacks.

The third article also deals with food production, from a more conventional perspective. Maize farmer preferences for intercropping systems to reduce Striga in Malawi reports findings on farmers' preferred options in managing Striga in Maize using discrete choice experiments.

Post-harvest losses to Insects can be qualitative. A fourth article, Measuring the nutritional cost of insect infestation of stored maize and cowpea, reports and analyse a rare study on the qualitative consequences of port-harvest insect infestation of two major African grains, maize and cowpea.

The fifth article, also dealing with food production, addresses the constraints of milk production, which is critical

Serge Savary

serge.savary@inra.fr

1 Institut National de la Recherche Agronomique, INRA, Auzeville, France in the combat of maternal and child under-nutrition. Linking calving intervals to milk production and household nutrition in Kenya. This study provides evidence that targeted onfarm specialization leads to significantly higher calving rates and shorter calving intervals, which in turn predictably increase milk production.

The sixth article deals with nutrition. Assessing food and nutrition security in Nepal: evidence from diet diversity and food expenditure patterns is a detailed analysis of the trends and patterns of change in the diversity in household diets using used multilevel modelling, quantile regression, and the Blinder-Oaxaca decomposition method.

The seventh article, also on nutrition addresses nutrition policies. Towards concerted government efforts? Assessing nutrition policy integration in Uganda provides a follow-up analysis of the efficacy of integrative policy strategies, using a novel policy integration perspective to investigate the extent to which eight ministries in Uganda integrated nutrition concerns across their policy outputs between 2001 and 2017.

The eighth article, The association between crop and income diversity and farmer intra-household dietary diversity in India, investigates the associations between crop and income diversity and dietary diversity among men, women, adolescents, and children of farmer households in India, using a very large sample of farmer households in two Indian states.

The ninth article also concerns food security in India, but from a urban perspective. Prevalence and correlates of household food insecurity in Delhi and Chennai, India also uses a very large sample to describe the prevalence of food insecurity in two major cities of India, to analyse the socioeconomic context of food insecurity in this context, and to compare the dietary intake of adults living in food insecure and food secure households.

The two next articles address the nature of food (in)security.

The ninth article, Household food insecurity is associated with depressive symptoms: results from a Mexican population-based survey, is a rare analysis of the linkages 
between food insecurity and depression. The article raises a methodological challenge - both depression and food insecurity are notoriously hard to measure - and a number of grave questions on the very nature of food insecurity, its causes, and its psychological dimensions.

The eleventh article, Household food insecurity is associated with depressive symptoms: results from a Mexican population-based survey, is a useful methodological analysis on the procedures to quantify food security in a urban context.

The gender component of food security is addressed in the twelfth article: To sell or consume? Gendered household decision-making on crop production, consumption, and sale in Malawi addresses the tension between self-consumption and sale of produced food in rural households.
Gender is also addressed in the thirteenth article. Women's access to agricultural extension and cropping practice in Timor-Leste provides a detailed, quantitative analysis of the conditions for women's access and participation to agricultural extension, which in turn, changes households'

cropping practice.

Economy and food security intervention is addressed in a fourteenth article. Impact of a food voucher program in alleviating household food insecurity in two cities in Senegal during a food price crisis reports the extent to which this type of intervention may help in times of economic crises, and provides insights for future interventions.

The last article of the issue, Multigrain noodles: nutritional fitness and cost effectiveness for Indian mid-day meal, is an example of nutritional intervention towards school children in India. 